
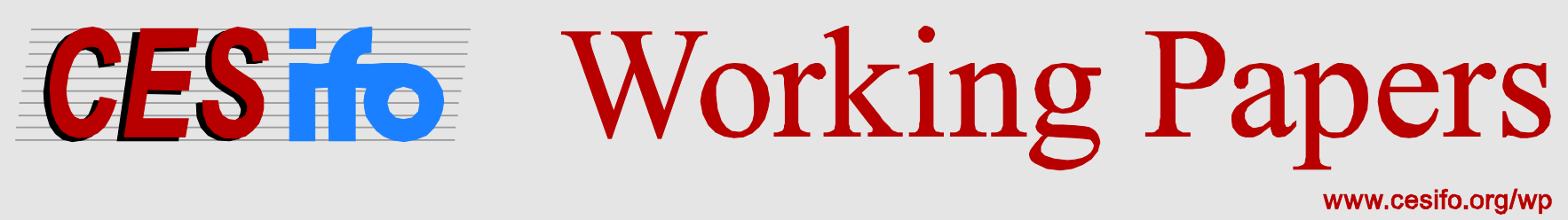

\title{
FRAND Royalties and Injunctions for Standard Essential Patents
}

\author{
Jay Pil Choi
}

CESIFO WORKING PAPER NO. 5012

CATEGORY 11: INDUSTRIAL ORGANISATION

OCTOBER 2014
An electronic version of the paper may be downloaded
- from the SSRN website: Www.SSRN.com
- from the RePEc website: Www.RePEc.org
- from the CESifo website: www.CESifo-group.org/wp




\title{
FRAND Royalties and Injunctions for Standard Essential Patents
}

\begin{abstract}
I develop a stylized model of court procedures that resolve disputes concerning FRANDencumbered standard essential patents (SEPs). I analyze the effects of injunctions and potential court-imposed FRAND rates on negotiated royalty rates. The SEP-holders' ability to hold-up is constrained by the prospect of the court-imposed license terms in case of disputes, but is not completely eliminated. Possible mechanisms to address the residual hold-up power of the SEP-holders are discussed.
\end{abstract}

JEL-Code: K410, L240, O300.

Keywords: standard essential patents, FRAND, injunctions. hold-up, patent litigation.

\author{
Jay Pil Choi \\ Department of Economics \\ Michigan State University \\ USA - 48824-1038 East Lansing MI \\ choijay@gmail.com
}

September 17, 2014

I thank participants in various conferences and seminars for helpful comments, and David Choi for editorial assistance. All errors, if any, are mine. This research was supported under Australian Research Council's Discovery Projects funding scheme (project number DP140100007). 


\section{Introduction}

Patents aim to protect and promote innovation by granting innovators exclusive rights to commercially exploit their inventions for a limited period of time. With such exclusive rights, a patent holder is entitled to damage payments if another party infringes on his patent without the patent holder's authorization or license. Patent holders are also entitled to seek an injunction against the alleged infringer, preventing further acts of infringement. ${ }^{1}$ However, for standard essential patents (SEPs), the availability of injunctive relief has been a contentious issue in high-tech industries where interoperability among various devices makes standards indispensable. In particular, one central policy question is whether the right to pursue injunctive relief should be extended to SEP owners who have made a commitment to license their essential patents on fair, reasonable and nondiscriminatory (FRAND) terms.

Views on this issue vary widely. One camp argues for no further restrictions on injunctions for SEPs than for non-SEP patents. In their view, the existing balancing test enunciated in eBay v. MercExchange is flexible enough to handle SEP cases, and thus a categorical treatment of SEPs is not justified (Denicolo et al., 2008; Wellford and McCutchen, 2012). An alternative view indicates that SEP owners should not be entitled to injunctive relief, as they had committed to FRAND as a condition to be included in the relevant standard (Lemley and Shapiro, 2007). In between, there is a wide spectrum of views concerning the extent to which the availability of injunctions should be constrained.

To address this issue, I develop a stylized model of a court-imposed dispute resolution mechanism in the context of standard essential patents (SEPs) with FRAND commitments. In particular, I analyze the effects of injunctions and potential court-imposed FRAND rates on negotiated royalty rates. The basic premise of this paper is that the negotiated royalty rate of a FRAND-encumbered SEP depends on both the framework in which the FRAND rate would be determined in the case of disputes and the availability of injunctive relief. In

\footnotetext{
${ }^{1}$ Until eBay $v$. MercExchange, an injunction order was issued more or less automatically in the absence of exceptional circumstances if a patent was found valid and infringed. However, in the landmark case of eBay, the Supreme Court unanimously ruled that the decision to grant an injunction should be based on traditional principles of equity. In particular, it can be denied if legal damages are "sufficient to compensate for the infringement and an injunction may not serve the public interest." See eBay, Inc. v. MercExchange, L.L.C., 547 U.S. 388 (2006).
} 
other words, the merits of the availability of injunctive relief cannot be assessed in isolation of the procedure and dispute settlement mechanisms in place to resolve any disputes that may arise between the SEP-holders and potential licensees concerning FRAND terms. I show that the SEP-holders' ability to hold-up is mitigated by the prospect of the courtimposed license terms, but is not completely eliminated. I discuss possible mechanisms to limit the residual hold-up power of the SEP-holders.

As products become more complex and sophisticated, they tend to encompass numerous complementary technologies, which brings to the forefront the issue of SEPs. In an increasingly networked environment, interoperability among various devices also plays an important role, which makes standards indispensable for many technological areas such as computers and telecommunications. Industry standards promote competition by ensuring compatibility and interoperability among products from different vendors. Standardization can be achieved in different ways. Sometimes it is an outcome of a decentralized market process in which a particular product is widely accepted as a "de facto" standard as more consumers gravitate towards it (e.g., Microsoft Windows). Alternatively, a government can mandate particular technical specifications as "de jure' standards (e.g., High Definition TV). In the majority of cases, however, the adoption of an industry standard is a result of negotiations by relevant stakeholders (such as vendors, engineers, and consumer groups) in a standard setting organization (SSO).

One potential issue with industry standards set by SSOs is that they may entail technologies covered by patents. In particular, there have been concerns that a patent included in a standard may have significant ex post market power. Before an industry standard is determined, there can be competing alternative technologies. However, once a standard has been chosen and industry participants have made investments specific to the chosen standard, alternative technologies become less attractive and may not be in a position to constrain the market power of the standard-essential patents. To safeguard against these potential hold-up incentives by the owners of SEPs, most SSOs require the owners of SEPs (i) to disclose their IP rights prior to the adoption of a standard, and (ii) to commit to license their essential patents on FRAND terms.

Despite the best efforts by SSOs to mitigate the ex post hold-up incentives with ex ante disclosure and FRAND commitments by SEP owners, it has proven difficult for an SSO to formulate and implement effective rules, as evidenced by increasing litigation concerning 
SEPs. This problem has been particularly acute with regard to FRAND commitments. One recent example is a dispute between Apple and Motorola (recently acquired by Google) concerning the terms of a license agreement on Motorola Mobility's patents essential to the H.264 (video codec) and IEEE 802.11 (WiFi) industry standards. Motorola insists that its $2.25 \%$ royalty demand is in line with its FRAND licensing obligations whereas Apple disputes that it is excessive. ${ }^{2}$

As illustrated by the dispute between Apple and Motorola, one main reason for the prevalence of disputes concerning FRAND terms is in the ambiguity of what "reasonable" means. ${ }^{3}$ Different interpretations of a reasonable royalty rate for different parties can lead to failed licensing negotiations, which results in litigation between SEP owners and a party that produces a product conforming to the industry standard. ${ }^{4}$

In analyzing the negotiation and litigation incentives of SEP owners, it is important to understand that a crucial factor in the determination of the royalty rate are the remedies available to the SEP owners when potential infringement on their patents takes place. The reason is that the negotiation between an SEP owner and an alleged infringer takes place in the shadow of litigation and the damage rule applied to patent infringement. In particular, the threat of an injunction bestows a strong bargaining position to the patent owners in licensing negotiations, as demonstrated by the patent infringement case between NTP, Inc. and Research in Motion (RIM). As articulated in an FTC report, "the patentee can use the threat of an injunction to obtain royalties covering not only the value of its invention compared to alternatives, but also a portion of the costs that the infringer would incur if it were enjoined and had to switch." ${ }^{5}$ This possibility of overcompensation to the patentee based on hold-up value is especially acute for SEPs that constitute only a limited number of features in the infringing product (Shapiro, 2010). In this regard, one important question to address is whether the SEP owners are entitled to injunctive relief against implementation of the standard when they have made FRAND commitments.

To answer the question of whether and under what circumstances injunctive relief should be available to the owners of SEPs, it is essential to discuss the framework that determines

\footnotetext{
${ }^{2}$ Apple v. Motorola (No. 1:11-cv-08540 ), N.D. IL., June 22, 2012.

${ }^{3}$ According to Robert McDowell, former FCC Commissioner, "reasonable" is not only a subjective term but "perhaps the most litigated word in American history." (Wall Street Journal, April 26-27, 2014).

${ }^{4}$ See Carlton and Shampine (2013) for a discussion of how the "non-discriminatory" component of FRAND can mitigate the hold-up problem when the "reasonable" principle fails to do so.

${ }^{5}$ Federal Trade Commission (2001), p. 144.
} 
the FRAND in case of disputes. Without any such mechanism in place, FRAND commitments simply have no meaning. Suppose that injunctive relief is available for SEP holders as in the case of regular patents; it is then clear that FRAND commitments are completely meaningless and provide no protection for SEP implementers from injunction threats unless there is a mechanism to determine an appropriate FRAND rate when the disputing parties cannot agree on one. With the availability of injunctive relief, the SEP holder can simply demand an infinite royalty rate and refuse to accept any royalty offers from the implementers, which leads to impasse in the negotiation, and thus FRAND has no bite in this context.

Now suppose that injunctive relief is categorically not allowed for SEPs as advocated by many people who are concerned with the hold-up problem. In this case, we can have a reverse hold-up problem. ${ }^{6}$ Without any mechanism to determine the FRAND rate, the implementers can simply refuse to pay any royalties and SEP owners will have no recourse and their incentives to innovate ex ante would be seriously undermined. This logic is consistent with Judge Posner's statement that an injunction against the infringing defendant would be justified if the defendant "refuses to pay a royalty that meets the FRAND requirement."7 Of course, the two scenarios discussed above are both extreme, and in reality the court will determine the FRAND rate and appropriate damage payments in the case of disputes, and bargaining will take place in the shadow of such expected FRAND rate determination. It is essential to discuss the effects of injunctive relief in conjunction with the framework that determines FRAND rates in the event of disputes.

I thus present a stylized model of a court which grants injunctions when the court finds that an SEP owner has offered a FRAND rate, but the implementer has refused to accept it. More specifically, I consider the following court proceeding. When an SEP owner and an implementer of the technology cannot agree on the FRAND rate, the court intervenes and first determines if the licensing rate offered by the SEP owner is FRAND. If it is deemed to be FRAND, the SEP owner has fulfilled its obligation to offer FRAND rates and is entitled to injunctive relief (and the parties can further negotiate under the shadow of injunction). If it is not FRAND, the court sets a FRAND rate. This procedure respects the private parties' right to contract and minimizes court intervention. It is also consistent with the

\footnotetext{
${ }^{6}$ See Langus, Lipatov, and Neven (2013) for a related discussion.

${ }^{7}$ Apple v. Motorola (No. 1:11-cv-08540 ), N.D. IL., June 22, 2012.
} 
current court practice in the US and Europe ${ }^{8}$, and is the prevailing view at the Department of Justice. For instance, a joint statement by the US Department of Justice and Patent Office (2013) states that they do not always "counsel against the issuance of an exclusion order to address infringement of a F/RAND-encumbered, standards-essential patent" and an exclusion order would be appropriate "if a putative licensee refuses to pay what has been determined to be a F/RAND royalty."

In this framework, the implementer has legal recourse to rely on a court-determined FRAND rate if the SEP owner's demand is excessive. This mechanism provides the implementer a measure of protection against the SEP-holder's ability to hold-up. Nonetheless, uncertainty associated with the court-determined FRAND rate and potential injunction threats tip the balance of bargaining power towards the SEP-owner, which leads to an elevated license rate that overcompensates the SEP-owner. I show that how a modified mechanism in which injunction is issued with "leniency" can restore the proper balance between the implementer and the SEP-owner. In particular, the analysis suggests that the court should be more lenient towards the implementer and more strict in imposing injunctions as a remedy when innovation is incremental and the court is less able to assess the FRAND rate precisely.

Ratliff and Rubinfeld (2013) develop a related model, but with a different conclusion. They model a dispute between a SEP owner and an implementer of the standard over the licensee fee and argue that an injunction threat does not necessarily lead to hold-up because the implementer has the option to accept licensee terms that are determined by a court and thus avoid injunction. In other words, an injunction threat kicks in only when the implementer refuses to accept the court-determined licensing terms. Thus, the initial negotiation between the SEP owner and the implementer does not arise in the shadow of an injunction threat even if it is available, but in the shadow of the expected courtdetermined FRAND rate. One crucial consequence of the Ratliff and Rubinfeld timing assumption is that the implementer is given an unfair advantage in the royalty negotiation; the implementer has nothing to lose by refusing the initial offer by the SEP-holder, because the implementer always has the option to accept the initial offer once it is certified to be FRAND while the implementer gains in the other case where it is found not to be FRAND.

Langus, Lipatov, and Neven (2013) also relates to this paper. They develop a model

\footnotetext{
${ }^{8}$ See Cotter (2013) for an overview.
} 
of court-granted injunctions to analyze the effects of injunctions on royalty negotiations for SEPs. As in my model, they assume that courts grant injunctions only when they believe that the prospective licensee is unwilling to license SEPs at the rate which the courts believe to be FRAND. However, they assume that the licensee is given a second chance to make an offer once its initial offer is found to not be FRAND. As a result, they find that "reverse hold-up" can arise in equilibrium in contrast to the conventional wisdom and the results derived in this paper.

Ganglmair, Froeb, and Werden (2012) develop a related model of FRAND commitments in which the court imposes damages on the patent holder if there is a breach of contract with excessive licensee fees. They show that a FRAND commitment can solve the hold-up problem, but also retards innovation. They propose an option-to-license contract in which the patent holder and the implementer agree on the license fee before the manufacturer invests, and show that such a mechanism solves the hold-up problem and is superior to the FRAND commitment mechanism in terms of maintaining the innovator's investment incentives. However, their option-to-license contract is not relevant if the infringement is made inadvertently.

Finally, a recent paper by Lerner and Tirole (forthcoming) show how structured price commitments by patent holders can deliver the ex ante competitive benchmark outcome and prevent ex post hold-up problems; FRAND is thus irrelevant in their framework without uncertainty. However, as they recognize, SSOs and (even patent holder themselves) may fail to identify relevant patents that later turn out to be essential to the standard. Structured price commitments and FRAND can be viewed as complements, and my analysis apples to cases where SSOs fail to identify relevant SEPs, even with structured price commitments in place.

The rest of the paper is organized as follows. In section 2 , I describe the nature of the hold-up problem for SEPs and the ambiguity associated with the FRAND commitments as a solution to the ex post hold-up problem. In section 3, I set up a stylized model of a court to resolve any disputes concerning the FRAND rate between the SEP owner and the implementer. It is shown that the SEP-holders' ability to hold-up is limited by the prospect of the court-imposed licensing terms, but is not completely eliminated. Section 4 proposes a potential mechanism to mitigate the residual hold-up problem. Concluding remarks are provided in section 5 . 


\section{The Economics of Ex Post "Hold-Up" by SEPs}

To set the stage for discussion of the need for FRAND commitments by SEP owners and the impact of injunctive relief on licensing negotiations, I first present a very simple model of hold-up by SEP owners. The model is a simple variation of Shapiro (2010) and formalizes the ideas in Carlton and Shampine (2013). ${ }^{9}$

For simplicity and to focus on the hold-up issue, I assume that the SEP owner and the implementer are in a vertical relationship and do not directly compete. For instance, the SEP owner is a pure research firm that is not engaged in any production of devices that implement the standard. Thus, I do not address the case where the injunction threat can be cancelled out due to both parties' need to cross-license and ensure reciprocal access to each other's patent portfolios. It also allows me to abstract from foreclosure incentives in the downstream market.

SEPs are patents which have been declared to be essential to the implementation of a standard by an SSO. By definition, they will be very difficult to design around, if not impossible. Otherwise, they would not be deemed essential to begin with. ${ }^{10}$ However, we need to distinguish ex ante vs. ex post essentiality. Prior to the adoption of a particular standard, there may have been multiple competing technologies that would have been capable of performing similar functionalities as the one actually included in the standard. Thus, prior to the selection of a particular standard, no technology or patents running on it may be essential. ${ }^{11}$ Once a particular standard has been selected and universally adopted by industry participants and the market, however, it would be economically infeasible to switch to another technology; this makes certain patents ex post essential in the implementation of the standard, which can confer a significant bargaining power to SEP owners. ${ }^{12}$ There is a widespread consensus among economists and legal scholars that SEP owners should be entitled to royalty rates based on the ex ante value of their technologies, not based on ex post bargaining power that arises from the ability to impose injunctions. This emerging

\footnotetext{
${ }^{9}$ See also Denicolo et al. (2008) for a related discussion.

${ }^{10}$ Commenting on a standard essential patent pertaining UMTS telecommunications capability, Circuit Judge Posner states that without it, "it would not be a cell phone." (italics original). See Posner's Opinion and Order of June 22, 2012 in the United States District Court for the Northern District of Illinois, Eastern Division (No. 1:11-cv-08540), p. 19.

${ }^{11}$ Lerner and Tirole (forthcoming) use the analogy of "putty-clay" to describe the ex ante vs. ex post environments.

${ }^{12}$ See Farrell et al. (2007) and Lerner and Tirole (forcoming).
} 
consensus view is best described by the FTC:

High switching costs combined with the threat of an exclusion order could allow a patentee to obtain unreasonable licensing terms despite its RAND commitment, not because its invention is valuable, but because implementers are locked in to practicing the standard. The resulting imbalance between the value of patented technology and the rewards for innovation may be especially acute where the exclusion order is based on a patent covering a small component of a complex multicomponent product. In these ways, the threat of an exclusion order may allow the holder of a RAND-encumbered SEP to realize royalty rates that reflect patent hold-up, rather than the value of the patent relative to alternatives, which could raise prices to consumers while undermining the standard setting process. ${ }^{13}$

To illustrate this point, I first consider a benchmark case in which the royalty rates of SEPs are determined as part of ex ante competition to be included in the standard.

\subsection{Benchmark Case of Ex Ante Competition}

There are two competing substitute technologies, $A$ and $B$, which can be potentially included in the standard. I assume that technology $A$ is patented whereas technology $B$ can be either competitively supplied or patented by another firm. Suppose that the inclusion of technologies $A$ and $B$, respectively, confers a net benefit of $V$ and $v$, where $V>v$. That is, I assume that technology $A$ is (weakly) superior to $B$ without any loss of generality and denote the advantage of $A$ over $B$ by $\Delta=V-v(>0)$.

Consider (ex ante) competition between technologies $A$ and $B$ to be included in the standard. The owners of the technologies compete in terms of royalty rate once they are included in the standard. I assume that all information is common knowledge and assume away any informational imperfection that may exist between the SSO and the technology owners.

\footnotetext{
${ }^{13}$ Third Party United States Federal Trade Commission's Statement on the Public Interest filed on June 6, 2012 in In re Certain Wireless Communication Devices, Portable Music \& Data Processing Devices, Computers and Components Thereof, Inv. No. 337-TA-745, available at www.ftc.gov/os/2012/06/1206ftcwirelesscom.pdf
} 
Betrand type price competition implies that technology $A$ will be chosen at the royalty rate of $\Delta$ in equilibrium. In this idealistic setting, the royalty rate of standard-essential patents $A$ reflects the ex ante value of its superiority over the next best alternative available, which is its true economic value.

\subsection{Ex Post Hold-Up}

For a variety of reasons, royalty rates are in most cases negotiated ex post the standardization process. For instance, technologies evolve over time and there can be a genuine uncertainty about the importance and relevance of particular patents down the road. This would be particularly relevant in high-tech industries with fast-paced innovations. In addition, as firms accumulate an enormous amount of related patents in diverse technology fields, it may be impractical to identify all relevant patents to prevent inadvertent infringement. ${ }^{14}$ In such a case, I analyze how the licensing fee negotiated ex post can substantially deviate from the ex ante benchmark rate derived above.

Consider a downstream firm that implements the standard that includes essential patent A. I envision a situation in which the downstream firm's product is a complex one that contains multiple technologies and patent $A$ constitutes only a small part of them. For instance, the product can be a smartphone that incorporates a variety of technologies in the areas of wireless communication, GPS, camera, digital technology, high speed broadband, and so on. ${ }^{15}$ The patent I consider covers only one of the multiple areas. Suppose that the downstream firm's profit from its product is given by $\Pi$. The source of this profit can be from incorporation of many other technologies and its substantial investment in the design of the product and complementary technologies in addition to the inclusion of patented technology $A$. Let $\pi$ denote the downstream firm's profit if the standard had included competing technology $B$ and the downstream firm had designed its product based on technology $B$ instead of $A$. For simplicity, I assume that other sources of the profit is independent of which technology is included in the standard, that is, $\Pi-\pi=V-v=\Delta$. Therefore, $\Delta$ reflects the true value of technology A over the next best available one.

\footnotetext{
${ }^{14}$ Mulligan and Lee (2012) estimate that "it would require roughly 2 million patent attorneys, working full-time, to compare every firm's products with every patent issued in a given year" to avoid accidental infringement. See Choi and Gerlach (2013) for an economic analysis of patent portfolios.

${ }^{15}$ According to Drummond (2001), Senior Vice President and Chief Legal Officer of Google, a smartphone may contain as many as 250,000 patent claims.
} 
If, however, the licensing negotiation takes place after the downstream firm has sunk its investment, the threat of injunction by the SEP owner enables him to extract more than the economic value of the technology. We assume Nash bargaining between the SEP owner and the downstream firm with the total surplus split between the two equally. This implies that the ex post licensing fee will be negotiated at $\Pi / 2$. To reflect the situation in which the patent at stake covers only a minor part of the multi-component product, I assume $\Pi / 2>\Delta$. The difference between the ex post negotiated licensing fee and ex ante value reflects the SEP owner's hold-up value $H=\Pi / 2-\Delta>0$. We expect that the downstream product commands a higher margin as the downstream firm invests more to develop the product and produces a more sophisticated product that includes other features. With ex post bargaining, the more profitable the product becomes, the more is extracted by the SEP owner as the hold-up value $H$ increases. This obviously has a chilling effect on downstream firms' investment incentives and may ultimately undermine the successful implementation of standards.

\subsection{FRAND Commitments as a Solution to Ex Post Hold-Up}

In response to this potential hold-up problem, standard setting organizations often require that participants in the standardization process disclose any patents that are relevant to the standard and commit to license SEPs on FRAND terms. For instance, the European Telecommunications Standards Institute (ETSI), which is officially recognized by the European Union as a European Standards Organization and produces globally-applicable standards for Information and Communications Technologies (ICT), stipulates:

When an ESSENTIAL IPR relating to a particular STANDARD or TECHNICAL SPECIFICATION is brought to the attention of ETSI, the DirectorGeneral of ETSI shall immediately request the owner to give within three months an irrevocable undertaking in writing that it is prepared to grant irrevocable licences on fair, reasonable and non-discriminatory ("FRAND") terms and conditions...16

However, it does not provide any specific royalty rate for a FRAND license, which is the case for most SSOs. In addition, the definition of FRAND is vague and elusive to pin

\footnotetext{
${ }^{16}$ ETSI Rules of Procedure, 20 March 2013, Annex 6: ETSI Intellectual Property Rights Policy, pp. 35-36.
} 
down, as explained below.

\subsection{Determination of FRAND Terms}

The main source of disputes arises from the meaning of FRAND as it can be interpreted in widely different ways. Obviously, what is "fair and reasonable" can be very difficult to define. The "non-discriminatory" component of FRAND at first may seem to be noncontroversial and easy to interpret. However, even this component of FRAND can be problematic. For instance, is a uniform royalty rate of $5 \%$ to everyone on the price of the product that contains the technology non-discriminatory? It may be considered as nondiscriminatory because everyone pays a $5 \%$ royalty, but the actual royalty payments can differ across licensees depending on the value of the products even though the percentage rate may be the same. To give an example, suppose that the same UMTS technology is incorporated in a simple phone sold at $\$ 50$ and in a smartphone sold at $\$ 500$. With a $5 \%$ royalty rate, the simple phone manufacturer will pay a royalty payment of $\$ 2.5$ whereas the smartphone manufacturer will pay $\$ 25$ for each phone sold. Is this contract nondiscriminatory? The emerging consensus on this seems to be that "similarly situated" licensees should pay similar amounts, leaving the possibility of charging different prices for very different devices. Nonetheless, what constitutes similarity can still be subject to different interpretations even if this principle is agreed upon. ${ }^{17}$

The "reasonable" component of FRAND is a much more difficult term to define and presents a fertile ground for disputes between the patent holder and the potential licensee, as no SSOs specify exactly what terms are "reasonable and fair," leaving the determination to courts [Lemley (2002) and Gilbert (2011)]. As a result, when the SEP owner and a downstream implementer negotiates a licensing fee, they will do so in the shadow of litigation. How their disputes will be settled in court in the event that they cannot agree on FRAND terms affects the negotiated licensing terms. However, determining what constitutes "fair and reasonable" in courts is much more challenging. As the interplay of court-determined FRAND rate and the availability of injunction determines the negotiated royalty rate, one contentious issue has been whether and under what conditions FRAND-

\footnotetext{
${ }^{17}$ See Gilbert (2011) and Carlton and Shampine (2013) for detailed discussion about the "nondiscriminatory" component of FRAND. They argue that the "non-discriminatory" prong of FRAND can provide meaningful protection against ex post hold-up while the "fair and reasonable" prong is inherently ambiguous and error-prone.
} 
encumbered SEPs are entitled to injunctive relief.

\section{A Stylized Model of FRAND Rate Disputes in Court}

I develop a stylized model of injunction for FRAND-encumbered SEPs to analyze the effects of injunction in the negotiated royalty rate. To reflect the current debate on the ex post hold-up value of SEPs, I construct a game where an allegedly infringing firm has already implemented the standard in its product. We can imagine a variety of scenarios in which this can happen. First, the infringement on the IPR of patent holders can be inadvertent in that the implementer sincerely believed that its device did not infringe on SEPs until the SEP holder approached him for infringement or the implementer was simply unaware of the existence of the patents. This scenario is particularly pertinent in the ICT sector where technologies are rapidly advancing and the development of new products requires access to and integration of numerous complementary technologies. In addition, the device manufacturer often develops the new products in secrecy for strategic reasons. For instance, Apple is notoriously known for its secrecy around new product developments and launches. The need for product development secrecy prevents a firm from negotiating a licensing contract with the SEP owners. To analyze the effects of injunction for FRAND-encumbered SEPs, we assume that the SEP owners have made FRAND commitments as a condition to be included in the standards. The game proceeds in the following sequence (see Figure 1).

Stage 1. The SEP owner and implementer engage in bargaining for licensing royalties. If they agree on a mutually acceptable rate, the game ends.

$\underline{\text { Stage } 2}$ (FRAND Determination by Court): If the two parties cannot agree on a licensing fee, then the court will determine if the offer made by the SEP owner (but rejected by the implementer) $r_{o}$ is FRAND. There are two cases to consider. ${ }^{18}$

(1) If $r_{o}$ is deemed to be FRAND by the court, the SEP-holder has fulfilled its FRAND obligation and is entitled to injunctive relief, as is the case for any other IP holders.

(2) If the court finds $r_{o}$ to not be FRAND, it will determine an appropriate FRAND rate $\widetilde{r}$.

\section{Stage 3.}

\footnotetext{
${ }^{18}$ Another possibility is that the court finds that the patents declared to be essential to the standard is not essential in the implementation of the standard or even invalid. We assume away this possibility by assuming that the essentiality and validity of SEPs are not an issue in the dispute.
} 
(1) If $r_{o}$ is deemed to be FRAND and an injunction is ordered in Stage 2, the implementer either leaves the market or can further negotiate with the SEP-holder in the shadow of an injunction threat.

(2) If the court imposes a FRAND rate $\widetilde{r}$, the implementer either accepts the FRAND rate or leaves the market.

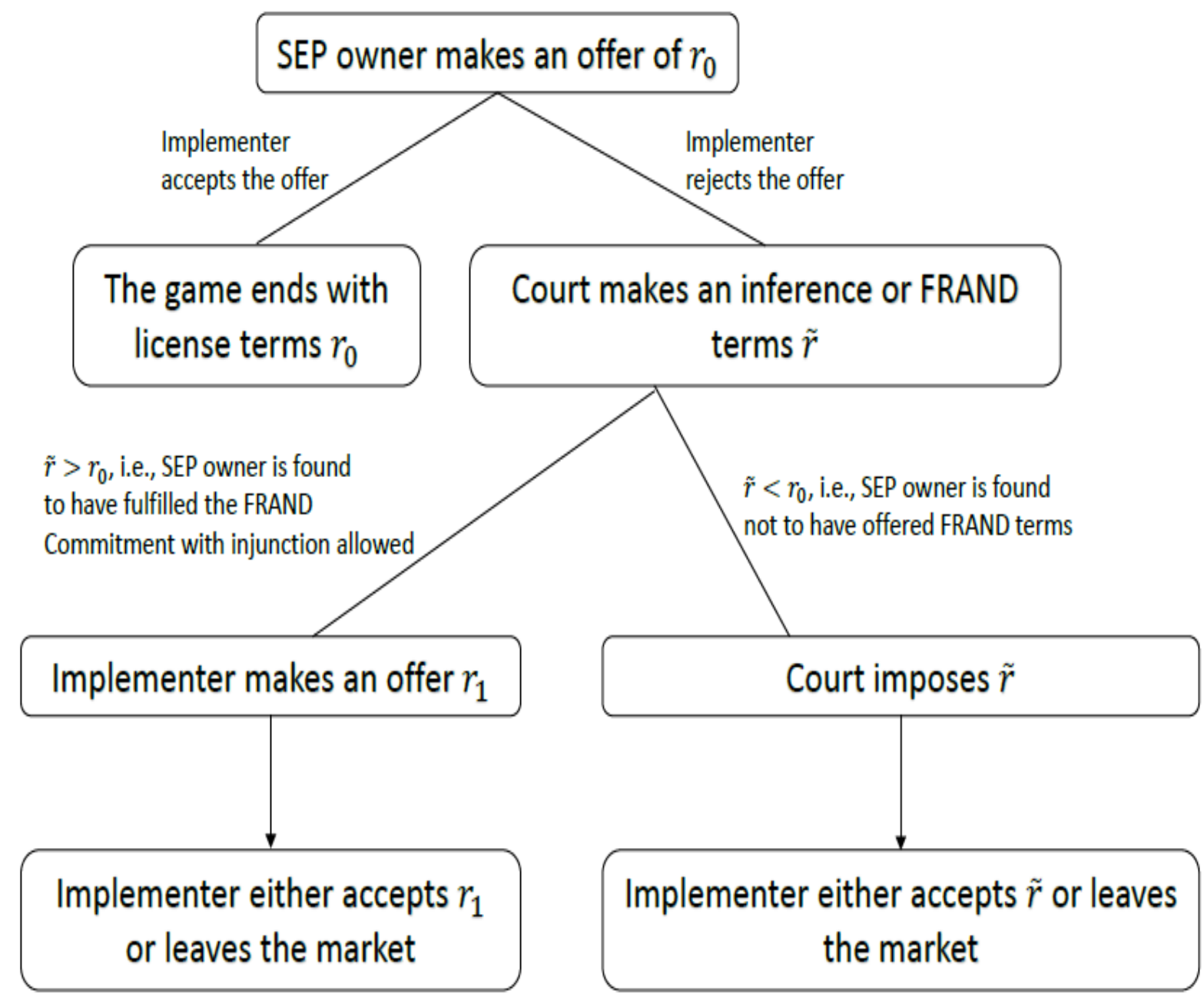

Figure 1: FRAND Dispute Resolution Sequence in Court

I assume that the information structure is symmetric. With efficient bargaining, the model predicts licensing, and litigation takes place only off the equilibrium path. As in Shapiro (2010), the main goal of the model is to analyze how the framework of FRAND determination and the availability of injunctive relief affects the terms of licensing for SEPs. It does not intend to analyze the conditions under which litigation takes place. 
Ratliff and Rubinfeld (2013) construct a similar model to analyze a dispute between the owner of a SEP and an implementer of the standard over FRAND. However, there is a major difference in assumptions about the timing of the availability of injunctive relief. In particular, they assume that when the initial offer by the SEP-holder is certified to be FRAND by the court, the implementer has an option to accept the initial offer $r_{o}$, and injunction can be invoked only when the implementer refuses to accept the FRAND rate. This ability to rely on the initial offer or the court-imposed FRAND rate as a last resort leads them to conclude that injunction threats for FRAND-encumbered SEPs do not lead to hold-up. The problem with the Ratliff and Rubinfeld timing is that the implementer has nothing to lose by refusing the initial offer by the SEP-holder, because the implementer always has the option to accept the initial offer once it is certified to be FRAND while the implementer gains in the other case where it is found not to be FRAND.

In contrast, I assume that once the initial offer is certified to be FRAND, the SEPholder is entitled to injunctive relief because he has fulfilled his FRAND pledge, and further negotiation takes place under an injunctive threat, which provides incentives for the implementers to accept FRAND offers when they are initially offered. This is consistent with the prevailing court procedure. In other words, the court does not issue an injunction order prior to resolution of the dispute over the FRAND rate in the court. The court imposes injunction only when it finds that the initial offer made by the SEP owner is FRAND and the infringer refused to accept the contract. ${ }^{19}$

One remark on the dispute resolution procedure is in order. I assume that the court procedure is asymmetric in the sense that the court imposes a FRAND rate on the implementer only when the initial offer by the SEP-holder is excessive compare to the FRAND rate. When the initial offer is considered to be below the court-inferred FRAND rate, the court does not impose its inferred FRAND rate; the court rather issues an injunction and let the SEP-holder and the implementer bargain over the royalty rate in the shadow of injunctive relief. This procedure can be rationalized if we take into account the fact that the determination of a FRAND rate is time-consuming and costly. Thus, the court

\footnotetext{
${ }^{19}$ For instance, see Circuit Judge Posner's Opinion and Order of June 22, 2012 in the United States District Court for the Northern District of Illinois, Eastern Division (No. 1:11-cv-08540). Concerning Motorola's injunctive claim, he states, "I don't see how, given FRAND, I would be justified in enjoining Apple from infringing the '898 unless Apple refuses to pay a royalty that meets the FRAND requirement." (p. 18)
} 
adopts a two-step procedure. First, it determines whether the initial royalty rate offered by the SEP-holder falls within a reasonable range. ${ }^{20}$ If it is, the court offers injunctive relief to the SEP-holder and let the private parties determine the exact rate. However, if the initial offer is considered out of the reasonable range in the first step, the resolution of the dispute requires a further court intervention. In this case, the court engages in the second step of specifying a FRAND rate. This two-step procedure not only minimizes the court's involvement and costs, but also respects the SEP-holder's property rights as the court would prefer the private parties to work things out. ${ }^{21}$

\subsection{The Irrelevance of Injunctions with the Perfect Court}

For FRAND-encumbered SEPs, it needs to be determined whether the SEP owner has offered a FRAND contract before any injunctive relief can be issued. The determination of FRAND is prerequisite, and injunctive relief is invoked only when the alleged infringer refuses to pay the FRAND offer made by the SEP owner or the court-determined FRAND offer. If the court is perfect in that it is able to set the FRAND rate at the ex ante value of the SEP, then whether injunctive relief is available is irrelevant and there is no concern with the potential hold-up problem because the implementers of the standard can always rely on the court ex post if the SEP owner makes an unreasonable demand beyond its ex ante value.

In reality, however, the court is imperfect and it would be prohibitively expensive for a judge to come up with a precise estimate of the ex ante value of the disputed SEPs. In this case, the implementer cannot completely rely on the court when the SEP owner demands a royalty rate above the ex ante value because there is a possibility that the court overestimates the ex ante value and determines the SEP owner's demands to be FRAND. Nonetheless, I assume that the court never finds the FRAND rate to be above the maximum royalty rate the SEP owner can extract with the threat of injunction, which is given by $\frac{\Pi}{2}$.

\footnotetext{
${ }^{20}$ The International Trade Commission (ITC) provides another forum where a patentee can assert a patent infringement claim to stop the importation of infringing products (section 337 of the Tariff Act of 1930). In an ITC case, Administrative Law Judge David Shaw made a determination of unreasonableness without specifically determining a FRAND rate (Mueller, 2012).

${ }^{21}$ In this analysis, we do not considered delay and costs associated in assessing FRAND by the courts in order to focus on hold-up aspects created by injunction. In reality, court proceedings are long, and can be an eternity for fast-paced industries like ICT. When a legal procedure takes a long time, there can also be an issue of "hold-out" by the implementer. Lemley and Shapiro (2013) propose binding "baseball-style" arbitration as a dispute resolution mechanism.
} 
This assumption can be justified if we consider a situation in which the court has information about the market value of the end product produced by the implementer, but is uncertain about the SEP patent's ex ante contribution to the product. In other words, the uncertainty lies in "apportionment" of the value of the SEP. From the perspective of the SEP owner and a downstream implementer, this implies that the court-determined FRAND rate can be modeled as a random variable $\widetilde{r} \in\left[0, \frac{\Pi}{2}\right]$ with a distribution function $F($.$) . I assume that$ the court's assessment is unbiased in that the expected value of $\widetilde{r}$ is equal to the ex ante benchmark rate $\Delta$, i.e.,

$$
E(\widetilde{r})=\int_{0}^{\frac{\Pi}{2}} \widetilde{r} d F(\widetilde{r})=\Delta
$$

\subsection{The Interplay between Injunctive Relief and Court-Determined FRAND Rate}

With an imperfect court, the availability of injunctive relief matters under the dispute resolution mechanism I consider even when the court is unbiased. In this subsection, I analyze the interplay between injunctive relief and the court-determined FRAND rate and how injunctive relief leads to an elevated royalty rate. Then, I propose a modified dispute resolution mechanism that would induce the ex ante benchmark royalty rate as an equilibrium outcome of the ex post negotiation. I assume that the licensee accepts the contract if he is indifferent between accepting and rejecting the contract.

Lemma 1 When offered a royalty rate of $r_{o}$ by the SEP owner, the licensee accepts the contract if and only if $r_{o} \leq \bar{r}$, where $\bar{r}$ is a unique solution to $\bar{r}=\int_{0}^{\bar{r}} \widetilde{r} d F(\widetilde{r})+[1-F(\bar{r})] \frac{\Pi}{2}$. In addition, $\bar{r}>\Delta$.

Proof. The licensee's objective is to minimize the expected licensee fee. If the licensee accept the contract with a royalty rate of $r$, its licensee fee is simply $r$, the LHS of the equation above. The RHS of the equation represents the expected licensee payment when the licensee rejects the offer. If the court deems that the offered royalty rate $r$ exceeds the court-determined FRAND rate $\widetilde{r}$, the court will impose $\widetilde{r}$. However, if the court determines that the licensor offered a FRAND rate (i.e., $r_{o} \leq \widetilde{r}$ ), the SEP owner has fulfilled his FRAND obligation and is entitled to injunctive relief. This event takes place with a probability of $[1-F(r)]$. With injunction as a default option, the SEP owner and the licensee engage in Nash bargaining and split the surplus evenly with a licensing fee of $\frac{\Pi}{2}$. 
The uniqueness of $\bar{r}$ comes from the fact that the RHS is a decreasing function of $r$ while the LHS is an increasing function. More precisely, define a function $\varphi(r)=r-\left[\int_{0}^{r} \widetilde{r} d F(\widetilde{r})+\right.$ $\left.[1-F(r)] \frac{\Pi}{2}\right]$. It can be easily verified that $\varphi(r)$ is a strictly increasing function.

$$
\varphi^{\prime}(r)=1-f(r)\left[r-\frac{\Pi}{2}\right]>0 \text { for all } r \in\left[0, \frac{\Pi}{2}\right]
$$

In addition, $\varphi(r=0)=-\frac{\Pi}{2}<0$ and $\varphi\left(r=\frac{\Pi}{2}\right)=\frac{\Pi}{2}-\Delta>0$. Taken together, there is a unique $\bar{r}$ such that $\varphi(\bar{r})=0$. Moreover, $\varphi(r=\Delta)<0$ because $\int_{0}^{\Delta} \widetilde{r} d F(\widetilde{r})+[1-F(\Delta)] \frac{\Pi}{2}>$ $\int_{0}^{\frac{\Pi}{2}} \widetilde{r} d F(\widetilde{r})=\Delta$. Therefore, $\bar{r}>\Delta$.

Proposition 1 The optimal contract offered by the SEP owner has a licensing fee of $r^{*}=\bar{r}$ with $\bar{r}>\Delta$, which is accepted by the licensee.

Proof. Given Lemma 1, we know that any contract offer with $r>\bar{r}$ will be rejected by the licensee and the court will determine if $r$ is FRAND or not. In this case, the expected licensing fee for the SEP owner is $\left[\int_{0}^{r} \widetilde{r} d F(\widetilde{r})+[1-F(r)] \frac{V}{2}\right]$, which is decreasing in $r$ and thus maximized at $r=\bar{r}$ for $r \in[\bar{r}, \infty)$. In contrast, any contract offer with $r<\bar{r}$ will be accepted. Thus, the best contract to be accepted is $r^{*}=\bar{r}$. See Figure 2 .

This analysis reveals that the court rule assumed in this paper induces a royalty fee that is excessive from an economic viewpoint. In other words, the threat of injunction overcompensates the SEP owner even if it is encumbered by the FRAND commitment. The reason is that the court's estimation of the FRAND rate is inherently imprecise; there is a chance that the court may deem an initial offer by the SEP-owner to be FRAND and grant injunctive relief, even if the initial offer exceeds $\Delta$.

The next proposition characterizes the optimal expected licensing fee $\xi$ in case the initial offer is rejected by the licensee, but deemed to satisfy FRAND by the court. This leads one to seek a mechanism that would induce the equilibrium royalty rate that would be negotiated to be the true value of innovation $\Delta$. 


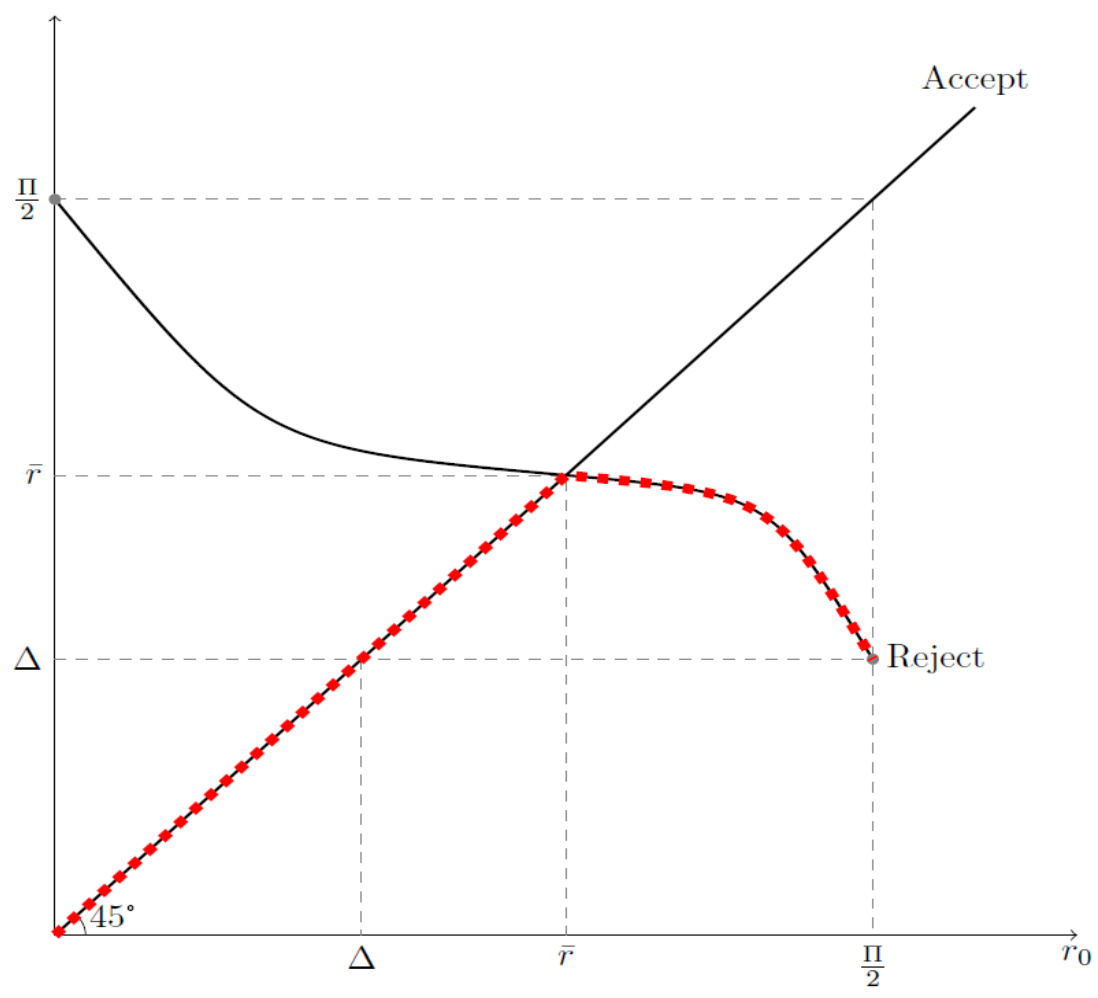

Figure 2: The Optimal Contract Offer by the SEP Owner

Proposition 2 Let $\xi$ be the (expected) licensing fee that would result in case the initial offer $r$ is rejected by the licensee, but deemed to satisfy FRAND by the court. The equilibrium offer by the SEP owner is then $r^{*}=\Delta$ if $\xi=\frac{\Delta-\int_{0}^{\Delta} \widetilde{r} d F(\widetilde{r})}{1-F(\Delta)}$.

Proof. By using the logic of the proof for Proposition 1, the equilibrium $r^{*}=\Delta$ if the following condition holds.

$$
\Delta=\int_{0}^{\Delta} \widetilde{r} d F(\widetilde{r})+[1-F(\Delta)] \xi
$$

Solving the equation above in terms of $\xi$ yields the desired result.

Proposition 2 implies that the negotiated royalty rate under an injunction threat exceeds $\xi$. However, a mechanism that induces such an expected licensing fee derived above would be difficult to implement. The next section proposes an alternative scheme to induce the ex ante value of innovation $\Delta$ as the equilibrium licensing fee in the initial negotiation. 


\section{Injunction with a Leniency Zone}

I propose the following modified mechanism. This mechanism specifies a leniency range in which injunction can be avoided even if the rejected royalty rate satisfies the FRAND commitment. More specifically, injunction is allowed only in the case where the licensee is thought to be unreasonably incalcitrant in refusing the SEP owner's offer. To formalize this, let $r$ be the SEP owner's offer, and the court's estimation of the FRAND rate to be $\widetilde{r}(>r)$. As a result, the SEP owner has offered a low enough royalty rate that satisfies the FRAND obligation. However, injunction is allowed only when the difference $(\widetilde{r}-r)$ exceeds a threshold value $\lambda$. If not, the court enforces the initial contract offered by the SEP owner $r$. We can interpret $\lambda$ as a parameter that represents the extent of a leniency zone. With this modified court rule, the expected royalty payment when an initial contract of $r$ is rejected is given by:

$$
\widetilde{\mu}(r ; \lambda)=\int_{0}^{r} \widetilde{r} d F(\widetilde{r})+[F(r+\lambda)-F(r)] r+[1-F(r+\lambda)] \frac{\Pi}{2}
$$

Once again, the optimal royalty rate $r^{*}$ offered by the SEP owner and accepted by the licensee satisfies the relationship $r^{*}=\widetilde{\mu}\left(r^{*} ; \lambda\right)$. Let $r^{*}(\lambda)$ be the solution. We would like to have the policy instrument $\lambda$ to induce $r^{*}(\lambda)=\Delta$. More specifically, we want $\lambda$ to be chosen to satisfy $\Delta=\widetilde{\mu}(\Delta ; \lambda)$, that is,

$$
\Delta=\int_{0}^{\Delta} \widetilde{r} d F(\widetilde{r})+[F(\Delta+\lambda)-F(\Delta)] \Delta+[1-F(\Delta+\lambda)] \frac{\Pi}{2}
$$

Proposition 3 There is a unique $\lambda^{*}$ that is implicitly defined by $\Delta=\widetilde{\mu}\left(\Delta ; \lambda^{*}\right)$.

Proof. It can be easily verified that $\widetilde{\mu}(\Delta ; \lambda)$ is decreasing in $\lambda$ because $\frac{\partial \widetilde{\mu}(\Delta ; \lambda)}{\partial \lambda}=-f(\Delta+$ $\lambda)\left(\frac{\Pi}{2}-\Delta\right)<0$. In addition, we know that $\Delta<\widetilde{\mu}(\Delta ; \lambda=0)$ whereas $\lim _{\lambda \rightarrow \infty} \widetilde{\mu}(\Delta ; \lambda)=$ $\left.\int_{0}^{\Delta} \widetilde{r} d F(\widetilde{r})+[1-F(\Delta)] \Delta<F(\Delta)\right] \Delta+[1-F(\Delta)] \Delta=\Delta$. Therefore, there exists a unique $\lambda^{*}$ such that $\Delta=\widetilde{\mu}\left(\Delta ; \lambda^{*}\right)$.

A simple comparative statics exercise yields the following sensible results.

Proposition $4 \frac{\partial \lambda^{*}}{\partial \Delta}<0$ and $\left|\frac{\partial \lambda^{*}}{\partial \Delta}\right|<1$ 
Proof. By totally differentiating $\Delta=\widetilde{\mu}\left(\Delta ; \lambda^{*}\right)$ with respect to $\Delta$ and $\lambda^{*}$, we have

$$
\frac{\partial \lambda^{*}}{\partial \Delta}=\frac{\{1-[F(\Delta+\lambda)-F(\Delta)]\}+f(\Delta+\lambda)\left(\frac{\Pi}{2}-\Delta\right)}{\frac{\partial \widetilde{\mu}(\Delta ; \lambda)}{\partial \lambda}}<0 \text { and }\left|\frac{\partial \lambda^{*}}{\partial \Delta}\right|<1
$$

because $\frac{\partial \widetilde{\mu}(\Delta ; \lambda)}{\partial \lambda}=-f(\Delta+\lambda)\left(\frac{\Pi}{2}-\Delta\right)<0$.

This implies that for incremental innovation, the court should be more lenient towards the licensee and more strict in imposing injunction as a remedy. I can also analyze how the precision in the court's assessment of the FRAND rate influences size of the leniency zone $\lambda$. I formalize the increase in the imprecision of the court's decision as a mean-preserving spread (MPS) of the distribution function $F$. More specifically, let the distribution function $F(\widetilde{r} ; \theta)$ be parametrized by $\theta$, with a higher $\theta$ representing less precision in the court decision (Rothschild and Stiglitz, 1970). I impose the following regularity restriction on the distribution function:

Single-Crossing-at-the Mean Condition (SCM). The distribution function of $\widetilde{r}$ corresponding to two different levels of imprecision $\theta$ and $\theta^{\prime}$, with $\theta^{\prime}>\theta$, intersect only once at the mean, that is, $F(\widetilde{r} ; \theta)-F\left(\widetilde{r} ; \theta^{\prime}\right) \gtreqless 0$, according to $\widetilde{r} \gtreqless E(\widetilde{r})=\Delta .^{22}$

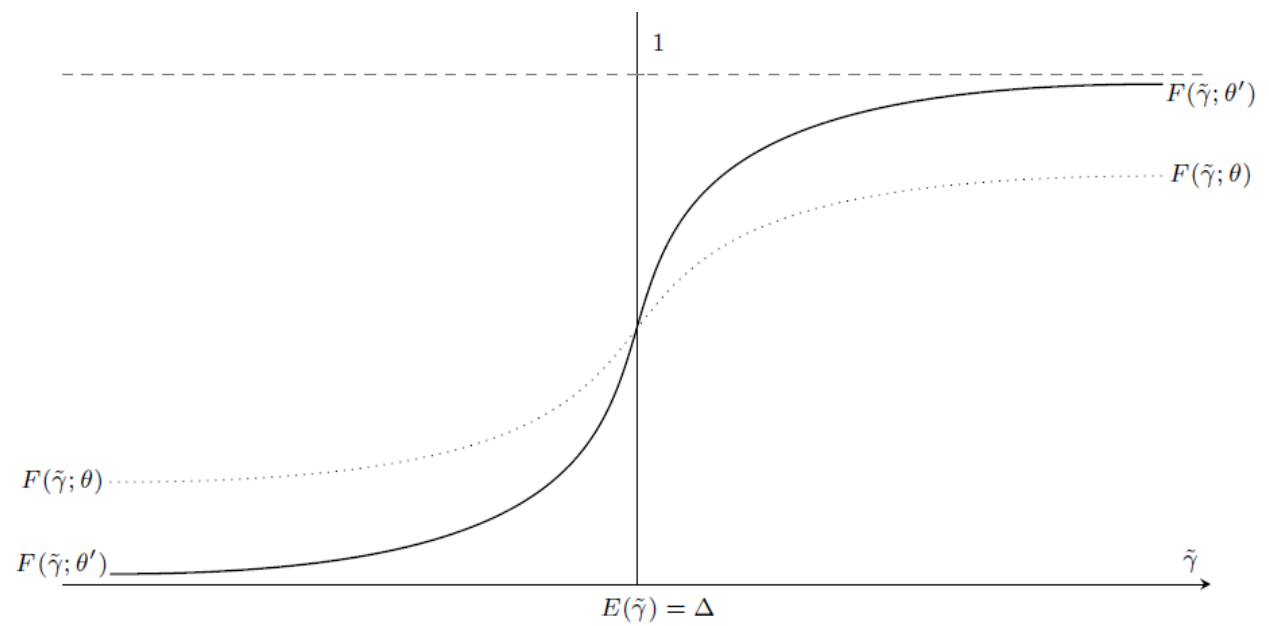

Figure 3: Mean-Preserving Spread with Single-Crossing-at-the-Mean

$$
\text { Condition }\left(\theta^{\prime}>\theta\right)
$$

\footnotetext{
${ }^{22}$ For instance, (truncated) normal distribution and uniform distribution satisfy my regularity condition if the variance is taken as imprecision parameter $\theta$. Note that I am not imposing a symmetry condition across the mean.
} 
Proposition 5 Let $\lambda^{*}(\theta)$ be the size of the leniency zone defined by $\Delta=\widetilde{\mu}\left(\Delta ; \lambda^{*}\right)$ corresponding to the level of court imprecision $\theta$. Then, $\lambda^{*}(\theta)$ is increasing in $\theta$. In other words, the leniency zone expands with the imprecision of the court assessment concerning the FRAND rate.

Proof. Let $\lambda^{*}(\theta)$ and $\lambda^{*}\left(\theta^{\prime}\right)$ be the size of the leniency zone corresponding to the level of court imprecision $\theta$ and $\theta^{\prime}$, respectively. Then,

$$
\begin{aligned}
\Delta & =\int_{0}^{\Delta} \widetilde{r} d F(\widetilde{r} ; \theta)+\left[F\left(\Delta+\lambda^{*}(\theta) ; \theta\right)-F(\Delta ; \theta)\right] \Delta+\left[1-F\left(\Delta+\lambda^{*}(\theta) ; \theta\right)\right] \frac{\Pi}{2} \\
\Delta & =\int_{0}^{\Delta} \widetilde{r} d F\left(\widetilde{r} ; \theta^{\prime}\right)+\left[F\left(\Delta+\lambda^{*}\left(\theta^{\prime}\right) ; \theta^{\prime}\right)-F\left(\Delta ; \theta^{\prime}\right)\right] \Delta+\left[1-F\left(\Delta+\lambda^{*}\left(\theta^{\prime}\right) ; \theta^{\prime}\right)\right] \frac{\Pi}{2}
\end{aligned}
$$

Suppose the contrary, i.e., that $\lambda^{*}(\theta)>\lambda^{*}\left(\theta^{\prime}\right)$ and $\theta^{\prime}>\theta$. Then,

$$
F\left(\Delta+\lambda^{*}(\theta) ; \theta\right)=F\left(\Delta+\lambda^{*}\left(\theta^{\prime}\right) ; \theta^{\prime}\right)
$$

since we have $\int_{0}^{\Delta} \widetilde{r} d F(\widetilde{r} ; \theta)=\int_{0}^{\Delta} \widetilde{r} d F\left(\widetilde{r} ; \theta^{\prime}\right)$ and $F(\Delta ; \theta)=F\left(\Delta ; \theta^{\prime}\right)$ by the (SCM) condition. However, $F\left(\Delta+\lambda^{*}(\theta) ; \theta\right)>F\left(\Delta+\lambda^{*}\left(\theta^{\prime}\right) ; \theta\right)>F\left(\Delta+\lambda^{*}\left(\theta^{\prime}\right) ; \theta^{\prime}\right)$. The first inequality follows from a property of the cumulative distribution function and the second one from the property of MPS. Therefore, we have a contradiction.

This implies that the court should be more conservative in issuing an injunction as a remedy for the SEP-owner when the court is less able to precisely assess the appropriate FRAND rate.

\section{Concluding Remarks}

Recent years have witnessed a dramatic increase in the number of disputes that involve standard essential patents. There has been a serious concern that SEP owners' ability to enjoin alleged infringers from selling infringing products creates an ex post hold-up problem. One important question is whether FRAND commitments can serve as an effective mechanism to constrain the ex post hold-up power of SEP owners in conjunction with the issue of whether and under what circumstances injunctive relief should be available to the owners of SEPs when they have made FRAND commitments. To answer this question, I have considered a very stylized model of patent disputes in which the court determines 
whether the SEP owner's contract offer is FRAND and an injunctive relief is offered only when the initial offer is indeed deemed to be FRAND. I show that the SEP-holder's ability to hold-up is limited by the prospect of the court-imposed licensing terms, but is not completely eliminated. I discuss possible mechanisms to address the residual hold-up power of SEP-holders. In particular, injunctive relief with a suitable leniency zone restores the balance of power and induces the ex ante value of the SEP as the equilibrium royalty rate that would be negotiated by the SEP owner and the implementer. As policy implications, the analysis suggests that the court should be more conservative in granting injunctive relief for the SEP-owner when the innovation is incremental and the court is less confident in its ability to precisely assess the FRAND rate. 


\section{References}

[1] Carlton, Dennis W. and Shampine, Allan, "An Economic Interpretation of FRAND," Journal of Competition Law and Economics, 2013, pp. 531-552.

[2] Choi, Jay Pil and Gerlach, Heiko, "A Theory of Patent Portfolios," CESifo Working Paper No. 4405, 3013.

[3] Cotter, Thomas, "The Comparative Law and Economics of Standard-Essential Patents and FRAND Royalties," Legal Studies Research Paper Series Research Paper No. 1340, University of Minnesota Law School, 2013.

[4] Drummond, David, "When Patents Attack Android," August 3, 2001, available at http://googleblog.blogspot.com/2011/08/when-patents-attack-android.html.

[5] Denicolo, Vincenzo, Geradin, Damien, Layne-Farrar, Anne, and Padilla, A. Jorge, "Revisiting Injunctive Relief: Interpreting eBay in High-Tech Industries with NonPracticing Patent Holders," Journal of Competition Law and Economics, 2008, pp. 571-608.

[6] Farrell, Joseph, Hayes, John, Shapiro, Carl, and Sullivan, Theresa, "Standard Setting, Patents, and Hold-Up," Antitrust Law Journal, 2007, pp. 603-670.

[7] Federal Trade Commission, The Evolving IP Marketplace: Aligning Patent Notice and Remedies with Competition, March 2001, available at http://www.ftc.gov/os/2011/03/110307patentreport.pdf.

[8] Ganglmair, Bernhard, Luke M. Froeb, and Gregory J. Werden (2012), "Patent HoldUp and Antitrust: How a Well-Intentioned Rule Could Retard Innovation," Journal of Industrial Economics, 2012, pp. 249-273.

[9] Richard J. Gilbert. "Deal Or No Deal? Licensing Negotiations In Standard-Setting Organizations" Antitrust Law Journal, 2011, pp. 855-888.

[10] Langus, Gregor, Lipatov, Vilen, and Neven, Damien, "Standard Essential Patents: Who is Really Holding Up (and When)?" Journal of Competition Law and Economics, 2013, pp. 253-284. 
[11] Lemley, Mark, "Intellectual Property Rights and Standard-Setting Organizations," California Law Review, 2002, pp. 1889-1906.

[12] Lemley, Mark and Shapiro, Carl, "Patent Hold-Up and Royalty Stacking," Texas Law Review, 2007, pp. 1991-2049.

[13] Lemley, Mark and Shapiro, Carl, "A Simple Approach to Setting Reasonable Royalties for Standard-Essential Patents," Berkeley Technology Law Journal, 2013, pp. 11351166.

[14] Lerner, Josh and Tirole, Jean, "Standard Essential Patents," Journal of Political Economy, forthcoming.

[15] Mueller, Florian, "Microsoft-Motorola FRAND Dispute Headed for November Jury Trial - No Summary Judgment," Foss Patents, June 6, 2012, available at http://www.fosspatents.com/2012/06/microsoft-motorola-frand-dispute-headed.html.

[16] Mulligan, Christina and Lee, Timothy B., "Scaling the Patent System," NYU Annual Survey of American Law, 2012, pp. 289-318.

[17] Ratliff, James and Rubinfeld, Daniel L., "The Use and Threat of Injunctions in the RAND Context," Journal of Competition Law and Economics, 2013, pp. 1-22.

[18] Rothschild, Michael and Stiglitz, Joseph E., "Increasing Risk: I. Definition," Journal of Economic Theory, 1970, pp. 225-243.

[19] Shapiro, Carl, "Injunctions, Hold-Up, and Patent Royalties," American Law and Economics Review, 2010, pp. 280-318.

[20] United States Department of Justice and United States Patent \& Trademark Office, "Policy Statement on Remedies for Standards-Essential Patents Subject to Voluntary F/RAND Commitments," January 8, 2013.

[21] Wellford, Hill and McCutchen, Bingham, "Reasons to Reject a 'No Injunctions' Rule for SEPs and FRAND-Obligated Patents," CPI Antitrust Chronicle, 2012, pp. 2-7. 